\title{
GENETICAL AND BIOCHEMICAL EVIDENCE THAT THE HYDROXYLATION PATTERN OF THE ANTHOCYANIN B-RING IN SILENE DIOICA IS DETERMINED AT THE p-COUMAROYL- COENZYME A STAGE
}

\author{
John Kamstreg, * Jan van Brederode and Gerrt van Nigtevecht \\ Department of Population and Evolutionary Biology, University of Utrecht, Padualaan 8, Utrecht, The Netherlands
}

(Received 31 October 1979)

Key Word ladez-Silene dioica; Caryophyllaceae; red campion; anthocyanin biosynthesis; pelargonidin and cyanidin glycosides; p-coumaroyl-CoA; caffeoyl-CoA; hydroxylation; genetic control.

\begin{abstract}
In petals of Silene dioica, gene $P$ controls the $3^{\prime}$-hydroxylation of the anthocyanin B-ring and the hydroxylation pattern of the hydroxycinnamoyl acyl group bound to the $4^{\mathrm{m}}$-hydroxyl group of rhamnose of anthocyanidin 3-rhamnosyl $(1 \rightarrow 6)$ glucoside-5-glucoside. In this paper, experiments are presented which show that gene $P$ is involved in the hydroxylation of $p$-coumaroyl-CoA to caffeoyl-CoA, which is then used both as a precursor in anthocyanin biosynthesis and as a substrate for the final acylation.
\end{abstract}

\section{INTRODUCTION}

Although considerable progress has been made in the elucidation of the biosynthesis of flavonoids [1], the level at which the hydroxylation pattern of the B-ring is determined is still in dispute. From the results of studies on flavonoid biosynthesis in Petunia hybrida, Hess [2-4] proposed that the substitution pattern of the B-ring is determined at the cinnamic acid stage, and persists throughout the biosynthetic pathway to produce the corresponding flavonoid. On the other hand, modifications in the substitution pattern of the B-ring have been demonstrated to occur also at the chalcone-flavanone, and later stages of the flavonoid pathway [1-5]. The hydroxylases [6] and phenolases $[7,8]$, which catalyse the hydroxylations both at the C-9 and C-15 stages, exhibit a broad substrate specificity. Additional criteria, e.g. genetic control or light stimulation, are therefore necessary to demonstrate their involvement in flavonoid biosynthesis.

In Silene dioica gene $P$ controls both the hydroxylation pattern of the B-ring of anthocyanins and the hydroxylation pattern of the acyl moiety. In petals of $P / P$ plants, cyanidin glycosides are acylated with caffeic acid, whereas in petals of $p / p$ plants the pelargonidin glycosides present are acylated with $p$ coumaric acid $[9,10]$. Thus gene $P$ is pleiotropic, since it controls both the hydroxylation of pelargonidin to cyanidin and the hydroxylation of the acyl group pcoumaric acid to caffeic acid. This effect can be explained by assuming that gene $P$ controls the conversion of $p$-coumaric acid to caffeic acid, which is used

* Present address: Department of Human Ecology, P.O. Box 8060, Wageningen, The Netherlands. both as a precursor for the biosynthesis of anthocyanins and for acylation.

Heinsbroek and van Brederode [11] demonstrated the presence of an enzyme in green parts of $S$. dioica plants which can catalyse the hydroxylation of $p$ coumaric acid to caffeic acid. This activity, however, is probably involved in the catabolism of cinnamic acid derivatives and not in the biosynthesis of anthocyanins. Maximal activity of the hydroxylating enzyme was found in the green parts, as distinct from the enzymes PAL, cinnamic acid 4-hydroxylase, $p$ coumarate CoA-ligase, flavanone synthetase, chalcone-flavanone isomerase (Bangma and Kamsteeg, unpublished results), anthocyanidin- and anthocyanin-glyoosyltransferases [12-14], which exhibit their maximal activity in opening flowers. Even more important is the fact that the activity of the enzyme was independent of the presence of gene $P$; both in $P / P$ and $p / p$ plants this activity was detectable.

In this paper experiments are presented which show that gene $P$ controls the activity of the enzyme $p$ coumaroyl-CoA, 3-hydroxylase, which catalyses the formation of caffeoyl-CoA from p-coumaroyl-CoA. In petals of $P / P$ plants, caffeoyl-CoA is then used both as a precursor for the biosynthesis of the anthocyanidin aglycone, cyanidin, and as a substrate for the enzyme hydroxycinnamoyl-CoA: anthocyanin 3-O-rhamnosylglucoside, $4^{m}$-hydroxycinnamoyltransferase. Further details of the enzymes involved will be published elsewhere.

\section{RESULTS AND DISCUSSION}

In order to locate the action of gene $\boldsymbol{P}$ more exactly, various anthocyanidin precursors were tested both in vitro and in vivo as substrates for the hydroxylation 
reaction and for their incorporation into anthocyanins. In in vitro experiments with a protein preparation of petals of $S$. dioica plants of the genotype $P / P$, various precursors were tested for their ability to act as substrate for the hydroxylation controlled by gene $P$. To circumvent the destruction of the rather unstable anthocyanidins, these compounds were converted to their more stable 3-O-glucosides. As the enzyme which catalyses this reaction (UDP-D-glucose: anthocyanidin 3-O-glucosyltransferase) is the only glucosyltransferase present in the genotype used, the anthocyanidin 3-O-glucosides formed are accumulated. This procedure has the additional advantage that, by using UDP-glucose labelled uniformly in the glucose moiety with a high specific activity, it is possible to detect even the smallest amounts of ${ }^{14} \mathrm{C}$-labelled anthocyanidin 3-O-glucoside. From the results presented in Table 1, it can be concluded that, in protein preparations of petals of buth $P / P$ and $p / p$ plants, $4^{\prime}$-hydroxy precursors are directly converted to pelargonidin 3-O-glucoside and $3^{\prime}, 4^{\prime}$-hydroxy precursors to cyanidin 3-O-glucoside. With all substrates tested, the anthocyanidin 3-O-glucoside formation was diminished by lowering the $\mathrm{pH}$. This decrease can be explained by the low activity of the 3-Oglucosyltransferase at low pHs. NADH, NADPH and ATP had no influence. These findings suggest that, at least in our in vitro system, 4'-hydroxy C-15 precursors cannot be hydroxylated. To circumvent the possible imperfections in our in vitro system, the same precursors were tested in vivo.

Stickland and Harrison [15] have shown that flowers of white-petalled $S$. dioica mutants rapidly form anthocyanins when fed with solutions of dihydroquercetin (taxifolin) or dihydrokaempferol. To obtain a better absorption of the precursor, we imbibed the claws of the petals. Also in this system no elaboration of the hydroxylation pattern occurred when naringenin, dihydrokaempferol or pelargonidin were administered to $P / P$ petals. The hydroxylation pattern of the anthocyanins formed corresponded with the hydroxylation pattern of the precursors fed.

Radiotracer experiments showed that caffeic acid and $p$-coumaric acid are also taken up by the claws of the petals, as can be concluded from their incorporation into anthocyanins, but their induction of anthocyanin is less pronounced. In petals of $p / p$ plants $p$-coumaric acid- $\left[\beta-{ }^{14} \mathrm{C}\right]$ was incorporated into pelargonidin glycosides and caffeic acid $-\left[\beta-{ }^{14} \mathrm{C}\right]$ into cyanidin glycosides. In petals of $P / P$ plants, $p$-coumaric acid mediates the formation of both pelargonidin and cyanidin glycosides. Caffeic acid initiated only the production of cyanidin glycosides. From these in vivo experiments it follows that in $P / P$ plants $p$-coumaric acid can be incorporated into cyanidin glycosides. In $p / p$ plants this incorporation was absent, but the petals still possess the ability to convert caffeic acid to cyanidin glycosides. It appears, therefore, that $p / p$ plants are unable to convert $p$-coumaric to caffeic acid. The only other compound which is involved in the biosynthetic pathway of flavonoids is the coenzyme $A$ ester of p-coumaric acid. This compound condenses with 3 units of malonyl-CoA to form a flavanone or chalcone. The enzyme which catalyses this reaction, flavanone synthetase, can use both $p$-coumaroyl-CoA and caffeoyl-CoA as substrate (Kamsteeg, unpublished results). If the hydroxylation of $p$-coumaroyl-CoA is controlled by gene $P$, the pleiotropic action of this gene can again be explained by the action of a single enzyme. The $3,4^{\prime}$-dihydroxyflavanone (eriodictyol) formed in $P / P$ plants can be further converted to cyanidin glycosides by the other enzymes involved in flavonoid biosynthesis. $p$-Coumaroyl-CoA and caffeoyl-CoA can both be used as substrate for the enzyme which catalyses the acylation of anthocyanins in S. dioica, hydroxycinnamoyl-CoA: anthocyanidin 3rhamnosylglucoside, $4^{\prime \prime \prime}$-hydroxycinnamoyltransferase. The $V_{\max }$ and the affinity of this enzyme for caffeoyl-

Table 1. The conversion of $\mathrm{C}-15$ precursors to anthocyanidin 3-O-glucosides by an enzyme preparation of petals of $P / P$ S. dioica plants

\begin{tabular}{|c|c|c|}
\hline \multirow[b]{2}{*}{ Substrate } & \multicolumn{2}{|c|}{$\begin{array}{c}\text { Activity (cpm) incorporated into } \\
3-O \text {-glucosides of }\end{array}$} \\
\hline & pelargonidin & cyanidin \\
\hline \multicolumn{3}{|l|}{ Chalcones } \\
\hline $4,2^{\prime}, 4^{\prime}, 6^{\prime}$-Tetrahydroxychalcone & 1431 & none \\
\hline $3,4,2^{\prime}, 4^{\prime}, 6^{\prime}$-Pentahydroxychalcone & none & $350^{*}$ \\
\hline \multicolumn{3}{|l|}{ Flavanones } \\
\hline Naringenin & 2758 & none \\
\hline Eriodictyol & none & $950^{*}$ \\
\hline \multicolumn{3}{|l|}{ Dihydroflavonols } \\
\hline Dihydrokaempferol & 3610 & none \\
\hline Dihydroquercetin & none & $1987^{*}$ \\
\hline \multicolumn{3}{|l|}{ Anthocyanidins } \\
\hline Pelargonidin & 87097 & none \\
\hline Cyanidin & none & 99743 \\
\hline
\end{tabular}

The assay mixture contained in a total volume of $50 \mu \mathrm{l}: 250 \mathrm{nmol} \mathrm{K-Na}$ phosphate buffer ( $\mathrm{pH} 7.5$ ), $100 \mathrm{nmol} \beta$-mercaptoethanol, $50 \mathrm{nmol}$ glucose-6-phosphate, $10 \mathrm{nmol}$ NADPH, 2 units glucose-6-phosphate dehydrogenase, $1.2 \mathrm{nmol}$ UDP-glucose-[U- ${ }^{14} \mathrm{C}$ ] $(300 \mathrm{Ci} / \mathrm{mol}), 100 \mathrm{nmol}$ substrate and $25 \mu /$ enzyme. The reaction mixture was incubated for $30 \mathrm{~min}$ at $30^{\circ}$.

* As only $50 \%$ of the synthesized substrate has the correct enantiomer for conversion, a lower incorporation was observed. 
CoA, however, is much higher than for p-coumaroylCoA (Hommels and Kamsteeg, unpublished results). That gene $\boldsymbol{P}$ may be involved in the hydroxylation of $p$-coumaroyl-CoA can be deduced from the finding that incubation of a protein preparation of petals of $P / P$ S. dioica plants with malonyl- $\left[\beta-{ }^{14} \mathrm{C}\right]-\mathrm{CoA}$ and $p$ coumaroyl-CoA in the presence of NADPH and UDP-glucose led to the formation of both pelargonidin 3-O-glucoside and cyanidin 3-O-glucoside, labelled in the anthocyanidin moiety (Table 2 ). In a protein extract of $p / p$ plants, however, only the formation of pelargonidin 3-O-glucoside could be detected. More

Table 2. The incorporation of hydroxycinnamoyl-Co $A$ esters into anthocyanidin 3-O-glucosides in enzyme preparations of petals of $P / P$ and $p / p S$. dioica plants

\begin{tabular}{lcc}
\hline \multicolumn{1}{c}{ Substrate } & $\begin{array}{c}\text { Activity (cpm) incorporated } \\
\text { into } 3-O \text {-glucosides of } \\
\text { pelargonidin }\end{array}$ & cyanidin \\
\hline $\begin{array}{l}\text { Genotype } P / P \\
\text { p-Coumaroyl-CoA }\end{array}$ & 181 & 3169 \\
Caffeoyl-CoA & none & 3547 \\
Genotype p/p & & \\
$p$-Coumaroyl-CoA & 3544 & none \\
Caffeoyl-CoA & none & 3859 \\
\hline
\end{tabular}

The reaction mixture contained in a total volume of $50 \mu \mathrm{l}$ : $250 \mathrm{nmol} \mathrm{K}-\mathrm{Na}$ phosphate buffer (pH 7.5), $100 \mathrm{nmol}$ UDPglucose, $25 \mathrm{nmol}$ malonyl $-\left[\beta-{ }^{14} \mathrm{C}\right]-\mathrm{CoA},(15 \mathrm{Ci} / \mathrm{mol}), 25 \mathrm{nmol}$ hydroxycinnamoyl-CoA, and $25 \mu \mathrm{l}$ enzyme, and was incubated for $30 \mathrm{~min}$ at $30^{\circ}$.

dircet evidence that gene $P$ is involved in the hydroxylation of $p$-coumaroyl-CoA to caffeoyl-CoA came from the following experiments. (i) When $p$-coumaric acid $-\left[\beta-{ }^{14} \mathrm{C}\right]$ together with coenzyme $\mathrm{A}$, ATP, NADPH and $\mathrm{MgCl}_{2}$ was incubated with a protein preparation of petals of $P / P$ plants, hydroxycinnamoyl-CoA esters were formed. Hydrolysis of these esters after purification yielded both ${ }^{14} \mathrm{C}$ labelled $p$-coumaric acid and caffeic acid. With a protein preparation of petals of $p / p$ plants, however, only $p$-coumaric acid was liberated (Table 3A). (ii) When $p$-coumaroyl- $\left[\beta-{ }^{14} \mathrm{C}\right]-\mathrm{CoA}$, synthesized and purified to a modified method of Gross and Zenk [16] (Hommels and Kamsteeg, unpublished results), was incubated with a protein preparation of $P / P$ plants in the presence of NADPH and FAD, caffeoyl-CoA was formed. In petals of $p / p$ plants this activity was absent (Table 3B).

\section{EXPERIMIENTAL}

Plant material. The growing conditions and the harvesting of plant material have been described before $[12,17]$.

Chemicals. UDP-glucose- $\left[\mathrm{U}-{ }^{14} \mathrm{C}\right](300 \mathrm{Ci} / \mathrm{mol})$ was supplied by the Radiochemical Centre, Amersham, U.K., malonic acid- $\left[\beta-{ }^{14} \mathrm{C}\right](46 \mathrm{Ci} / \mathrm{mol})$ and malonyl- $\left[\beta-{ }^{14} \mathrm{C}\right]-\mathrm{CoA}$ by NEN, Boston, MA. $p$-Coumaric acid- $\left[\beta-{ }^{14} \mathrm{C}\right]$ was synthesized from malonic acid $\left[\beta-{ }^{14} \mathrm{C}\right]$ and $p$-hydroxybenzaldehyde according to the Knoevenagel condensation using Py and a trace of piperidine for catalysis. Naringenin, dihydroquercetin, cyanidin and pelargonidin chloride were purchased from Carl Roth, A. G., Karlsruhe, Germany. Eriodictyol was synthesized from dihydroquercetin by reduction with $\mathrm{Zn}$
Table 3. The hydroxylation of hydroxycinnamoyl-CoA esters formed by enzyme preparations of petals of $P / P$ and $p / p$ S. dioica plants

\begin{tabular}{|c|c|c|}
\hline \multirow[b]{2}{*}{ Substrate } & \multicolumn{2}{|c|}{$\begin{array}{l}\text { Hydroxycinnamates liberated } \\
\text { after hydrolysis (nmol/assay) }\end{array}$} \\
\hline & p-Coumaric acid & Caffeic acid \\
\hline \multicolumn{3}{|c|}{ Formation and hydroxylation of $\mathrm{CoA}$ ester (A) } \\
\hline$p$-Coumaric acid & 1.78 & 1.76 \\
\hline Caffeic acid & none & 1.15 \\
\hline \multicolumn{3}{|l|}{ Genotype $p / p$} \\
\hline$p$-Coumaric acid & 1.58 & none \\
\hline Caffeic acid & none & 0.64 \\
\hline \multicolumn{3}{|c|}{ Hydroxylation of CoA ester (B) } \\
\hline \multicolumn{3}{|l|}{ Genotype $P / P$} \\
\hline$p$-Coumaroyl-CoA & 0.25 & 0.26 \\
\hline \multicolumn{3}{|l|}{ Genotype $p / p$} \\
\hline p-Coumaroyl-CoA & 0.54 & none \\
\hline
\end{tabular}

(A) The reaction mixture contained in a total volume of $1 \mathrm{ml}: 0.5 \mu \mathrm{mol}$ coenzyme A, $2.5 \mu \mathrm{mol}$ ATP, $2.5 \mu \mathrm{mol}$ $\mathrm{MgCl}_{2}, 250 \mathrm{nmol} p$-coumaric acid $\left[\beta-{ }^{14} \mathrm{C}\right](1.5 \mathrm{Ci} / \mathrm{mol})$ or caffeic acid- $\left[\beta-{ }^{14} \mathrm{C}\right](0.5 \mathrm{Ci} / \mathrm{mol})$ in $1 \% \mathrm{KHCO}_{3}, 1 \mu \mathrm{mol}$ NADPH (pH 7.5), $100 \mu \mathrm{mol}$ Tris- $\mathrm{HCl}(\mathrm{pH} \mathrm{7.5)}$ and $200 \mu \mathrm{l}$ enzyme. The reaction was incubated for $45 \mathrm{~min}$ at $30^{\circ}$.

(B) The reaction mixture contained in a total volume of $475 \mu \mathrm{l}$ : $5 \mathrm{nmol} p$-coumaroyl- $\left[\beta-{ }^{14} \mathrm{C}\right]-\mathrm{CoA}, \quad 0.26 \mu \mathrm{mol}$ NADPH, $0.18 \mu \mathrm{mol}$ FAD and $200 \mu l$ enzyme.

dust $/ \mathrm{HCl}$. Cyanidin 3-O-glucoside was isolated from petals of appropriate genotypes of $S$. dioica as described before [12]. Pelargonidin 3-O-glucoside was isolated from strawberries by the method of ref. [18]. The $4,2^{\prime}, 4^{\prime}, 6^{\prime}$-tetrahydroxychalcone was prepared from naringenin and $3,4,2^{\prime}, 4^{\prime}, 6^{\prime}$ pentahydroxychalcone from eriodictyol according to refs. $[19,20]$ or ref. [21].

Enzyme preparation. Five $\mathrm{g}$ petals were homogenized at $0-4^{\circ}$ with an all glass Potter-Elvehjem homogenizer in $5 \mathrm{ml}$ $20 \mathrm{mM} \beta$-mercaptoethanol, $5 \%$ soluble polyvinylpyrrolidone (MW 44000 ), 1\% Triton X-100, $50 \mathrm{mM} \mathrm{K-Na} \mathrm{Pi} \mathrm{buffer} \mathrm{(pH}$ 7.5 ) and centrifuged for $15 \mathrm{~min}$ at $38000 \mathrm{~g}$. The protein was purified from endogenous substrate by filtration over Polyclar AT (PVP) and Sephadex G-50 columns, which had been equilibrated before use with a $4 \mathrm{mM} \beta$-mercaptoethanol, $0.02 \%$ Triton $X-100,10 \mathrm{mM} \mathrm{K-Na} \mathrm{Pi} \mathrm{buffer} \mathrm{(pH} 7.5,6.8$ or $6.0)$. These buffers were also used for the elution of the protein. For the synthesis of hydroxycinnamoyl-CoA esters the enzyme was prepared accordin to the method of ref. [22] using Dowex $1 \times 2$.

Enzyme assays. Anthocyanin formation. After incubation of the reaction mixture as described in Tables 1 or 2 , the reaction mixture, together with carrier cyanidin 3-Oglucoside and pelargonidin 3-O-glucoside, was applied as a spot on Whatman No. 3 and developed 2-D in $n-B u O H-2 ~ N$ $\mathrm{HCl}(1: 1$, upper phase) and $1 \% \mathrm{HCl}$, respectively. The anthocyanin spots were cut out, placed in a scintillation vial with toluene liquifluor and counted in a liquid scintillation spectrometer. Formation of hydroxycinnamoyl-CoA esters. After incubation of the reaction mixture as described in Table 3, the reaction mixture, together with carrier $p$ coumaroyl-CoA and caffeoyl-CoA, was applied as a small band on Whatman No. 3 and developed in $n-B u O H-H O A c-$ $\mathrm{H}_{2} \mathrm{O}(5: 2: 3)$. The band containing the hydroxycinnamoyl$\mathrm{CoA}$ esters was cut out, eluted with formic acid (pH 2.5) and 
freeze-dried. The esters were hydrolysed with $0.1 \mathrm{~N} \mathrm{NaOH}$ for 1-2 min, and applied with reference $p$-coumaric acid and caffeic acid on Si gel $\mathrm{GF}_{254}$ plates and developed in $\mathrm{C}_{6} \mathrm{H}_{6}-p$ dioxane-HOAc $(90: 25: 4)$ ( $R_{y}$ caffeic acid $0.20 ; p$-coumaric acid 0.39 ). The spots were scraped off, put in a scintillation vial with a Lumagel-water mixture, and counted in a liquid scintillation spectrometer.

In vitro culture of petals. By immersing the petal claws in an aq. soln, the various anthocyanin precursors (flavanones, dihydroflavanols and anthocyanidins) were administered to the flower lobes. The induction of anthocyanin synthesis was perceptible within $3 \mathrm{hrs}$. The amount of induced anthocyanin formed depended on the age of the flower, but was normally $50-60 \mathrm{nmol}$ per flower ( 5 petals). As little as $2 \mathrm{nmol}$ should have been perceptible in white flowers.

Acknowledgements-The authors are much indebted to Prof. Dr. M. H. Zenk and Dr. B. Ulbrich, Lehrstuhl für Pflanzenphysiologie, Ruhr-Universität, Bochum, Germany, and Dr. R. Sütfeld, Botanisches Intitut der Westfälische WilhelmsUniversität, Münster, for kindly supplying samples of $p$ coumaroyl-CoA and caffeoyl-CoA. We also thank Dr. R. Cooper, Department of Chemistry, The Weizman Institute of Science, Rehovot, Israel, for his gift of dihydrokaempferol and Mr. C. H. Hommels for his assistance. The investigation was supported by a grant from the research pool of the University of Utrecht.

\section{RETERENCES}

1. Hahlbrock, K. and Grisebach, H. (1975) in The flavonoids. (Harborne, J. B., Mabry, T. and Mabry, H., eds.) pp. 866-915. Chapman \& Hall, London.

2. Hess, D. (1964) Planta 60, 568.

3. Hess, D. (1968) in Biochemische Genetik; eine Einführung unter besonderer Berücksichtigung höheren Pflanzen (Hess, D., ed.) pp. 23-29. Springer, Berlin.

4. Hess, D. (1967) Z. Pflanzenphysiol. SG, 12.
5. Grisebach, H. (1973) in Chemistry in Evolution and Systematics (Swain, T., ed.) pp. 487-511. Butterworths, London.

6. Fritsch, H. and Grisebach, H. (1975) Phytochemistry 14, 2437.

7. Vaughan, P. F. T., Butt, V. S., Grisebach, H. and Schill, L. (1969) Phytochemistry 8, 1373.

8. Roberts, R. J. and Vaughan, P. F. T. (1971) Phytochemistry 10, 2649.

9. Kamsteeg, J,, van Brederode, J. and van Nigtevecht, G. (1976) Phytochemistry 15, 1917.

10. Kamsteeg, J., van Brederode, J., Küppers, F. J. E. M. and van Nigtevecht, G. (1978) Z. Naturforsch. Teil C 33, 475.

11. Heinsbroek, R. and van Brederode, J. (1980) Phytochemistry 19, in press.

12. Kamsteeg, J., van Brederode, J. and van Nigtevecht, G. (1978) Biochem. Genet. 16, 1045.

13. Kamsteeg, J., van Brederode, J. and van Nigtevecht, G. (1978) Biochem. Genet. 16, 1059.

14. Kamsteeg, J., van Brederode, J. and van Nigtevecht, G. (1979) Phytochemistry 18, 659.

15. Stickland, R. G. and Harrison, B. J. (1977) Heredity 39, 327.

16. Gross, G. G. and Zenk, M. H. (1966) Z. Naturforsch. Teil B 21, 683.

17. van Nigtevecht, G. (1966) Genetica 37, 281.

18. Wrolstad, R. E., Hildrum, K. I. and Amos, J. F. (1970) J. Chromatogr. 50, 311.

19. Linke, H. A. B. and Everleigh, D. E. (1975) Z. Naturforsch. Teil B 30, 606.

20. Linke, H. A. B. and Everliegh, D. E. (1975) Z. Naturforsch. Teil B 30, 940.

21. Moustafa, E. and Wong, E. (1967) Phytochemistry 6, 625.

22. Lindl, T., Kreuzaler, F. and Hahlbrock, K. (1973) Biochim. Biophys. Acta 302, 457. 